\title{
Baixas concentrações de macronutrientes beneficiam a propagação in vitro de Vriesea incurvata (Bromeliaceae), uma espécie endêmica da Floresta Atlântica, Brasil
}

\author{
Low macronutrient concentrations benefit in vitro propagation of Vriesea incurvata \\ (Bromeliaceae), an endemic species of the Atlantic Forest, Brazil
}

\author{
Márcio Hisayuki Sasamori ${ }^{1}$, Delio Endres Júnior ${ }^{1}$ \& Annette Droste $e^{1,2}$
}

\begin{abstract}
Resumo
A cultura in vitro é uma ferramenta eficiente para a propagação de plantas de importância ecológica e econômica e permite o entendimento acerca de aspectos ecofisiológicos das espécies. Este estudo teve por objetivo avaliar a influência de diferentes concentrações de macronutrientes sobre o desenvolvimento in vitro e a sobrevivência ex vitro de plântulas de Vriesea incurvata, visando à conservação desta bromélia epifítica endêmica da Floresta Atlântica. A germinação in vitro foi avaliada aos 60 dias e as plântulas foram cultivadas por 180 dias em meio MS com 25 ou $50 \%$ dos macronutrientes, 25 ou $50 \%$ dos sais nitrogenados, bem como com $100 \%$ da formulação original do meio. As sementes apresentaram $95 \%$ de germinação. Em todos os tratamentos, houve 100\% de sobrevivência das plântulas cultivadas in vitro. A redução de todos os macronutrientes ou dos sais nitrogenados mostrou-se benéfica, proporcionando maior comprimento da parte aérea e da raiz maior, maior número de folhas e de raízes, bem como maior massa fresca, além de ter propiciado $97 \%$ de sobrevivência das plântulas aclimatizadas ex vitro. Os dados obtidos permitem o estabelecimento de um protocolo de propagação in vitro de $V$. incurvata, com o objetivo de sua futura reintrodução no habitat natural.
\end{abstract}

Palavras-chave: bromélias, conservação, micropropagação, nutrição mineral.

\begin{abstract}
In vitro culture is an efficient tool for the propagation of plants of ecological and economic importance and allows the understanding about ecophysiological aspects of the species. The objective of this study was to assess the influence of different macronutrient concentrations on in vitro development and ex vitro survival of Vriesea incurvata plantlets, aiming the conservation of this endemic epiphytic bromeliad from the Atlantic Forest. The in vitro germination was assessed at 60 days and the plantlets were cultivated for 180 days on MS medium with 25 or $50 \%$ of the macronutrients, 25 or $50 \%$ of the nitrogen salts, or with $100 \%$ of the original formulation of the medium. The seeds showed $95 \%$ germination. In all treatments, there was $100 \%$ survival of in vitro cultivated plantlets. The reduction of all macronutrients or of the nitrogen salts was beneficial, and permitted a greater length of the aerial part and of the major root, a higher number of leaves and roots, and more fresh mass, as well as allowed $97 \%$ survival of ex vitro acclimatized plantlets. The obtained data allow the establishment of a protocol for in vitro propagation of $V$. incurvata, aiming its future reintroduction into the natural habitat.
\end{abstract}

Key words: bromeliads, conservation, micropropagation, mineral nutrition.

\section{Introdução}

A Floresta Atlântica ocupa uma área de 1.315.460 km² (Fundação SOS Mata Atlântica 2015) ao longo da costa litorânea do território brasileiro, que se estende do Rio Grande do Norte ao Rio Grande do Sul (IBF 2015). Conhecido mundialmente como uma das áreas prioritárias para conservação (Myers et al. 2000), este bioma tem registrado crescente redução de sua cobertura vegetal (Fundação SOS Mata Atlântica \& INPE

\footnotetext{
${ }^{1}$ Universidade Feevale, Prog. Pós-graduação em Qualidade Ambiental, Rod. ERS-239 2755, 93525-075, Novo Hamburgo, RS, Brasil.

${ }^{2}$ Autor para correspondência: annette@feevale.br
} 
2014), atualmente restando apenas $7,91 \%$ de sua área original (IBF 2015). Bromeliaceae apresenta distribuição neotropical, com 58 gêneros e 3.248 espécies descritas (Luther 2010), das quais $40 \%$ são encontradas no território brasileiro (BFG 2015), sendo a segunda maior família de epífitos vasculares ocorrentes na Floresta Atlântica (Kersten 2010). As bromélias são consideradas um grupo taxonômico importante devido aos altos níveis de especialização, formando sistemas ecológicos complexos que contribuem para a manutenção da estabilidade dos ecossistemas florestais (Padilha 1978; Benzing 2000). Várias espécies desta família são endêmicas da Floresta Atlântica (Wanderley et al. 2006; Martinelli et al. 2008), e muitas figuram nas listas de espécies ameaçadas de extinção devido ao extrativismo e à degradação ambiental pela intervenção antrópica (Reitz 1983; Forzza et al. 2013).

Vriesea incurvata Gaudich. é uma bromeliácea endêmica do Brasil, ocorrente nas regiões Sul e Sudeste do Brasil, nos estados de Rio Grande do Sul, Santa Catarina, Paraná, São Paulo e Rio de Janeiro (BFG 2015). No Rio Grande do Sul, $V$. incurvata figura na lista de espécies da flora ameaçadas de extinção, na categoria de dados insuficientes para avaliação de seu risco (Rio Grande do Sul 2014) e no Paraná é uma das dez bromeliáceas mais coletadas ilegalmente e comercializadas para ornamentação (Negrelle \& Muraro 2006). A espécie é herbácea, de hábito epifítico, raramente rupícula, com altura máxima de $50 \mathrm{~cm}$, apresentando cerca de 10 folhas, dispostas em roseta, lisas e sem espinhos (Reitz 1983). A sua inflorescência é submultifloral, espigada, com altura entre 30 a $40 \mathrm{~cm}$ (Negrelle \& Muraro 2006) (Fig. 1f). Geralmente, V. incurvata é encontrada na parte mediana inferior dos forófitos, preferencialmente em ambiente de luz difusa (Reitz 1983), de forma isolada ou em pequenos agrupamentos formados por brotações laterais, no interior do sub-bosque e em beiras de cursos d'águas (Bourscheid 2008).

As sementes produzidas pelas bromélias epifíticas apresentam baixa capacidade de germinação em ambiente natural (Mekers 1977; Mercier \& Kerbauy 1995), uma vez que necessitam de condições adequadas específicas de microclima e substrato (Winkler et al. 2005). Além disso, o estabelecimento das plântulas nos anos iniciais tem sido considerado o estádio mais vulnerável do ciclo de vida das bromélias, levando a altas taxas de mortalidade das plântulas (Harper 1977; Winkler et al. 2005). O uso de ferramentas biotecnológicas é uma alternativa importante para a conservação de espécies (Grattapaglia \& Machado 1998), uma vez que a cultura in vitro permite elevadas taxas de germinação das sementes de forma rápida e eficiente quando comparada ao ambiente natural (Mercier \& Kerbauy 1995; Pedroso-de-Moraes et al. 2009), além de proporcionar a manutenção da variabilidade genética das plântulas (Mercier \& Kerbauy 1995; Pinto et al. 2010). Contudo, a maioria dos estudos de micropropagação de bromeliáceas utilizam reguladores de crescimento para indução e multiplicação de brotos, gerando indivíduos geneticamente homogêneos, inadequados para fins conservacionistas.

A micropropagação, em função da disponibilidade de água e nutrientes, bem como das condições livres de patógenos, apresenta vantagens quando comparada com as propagações convencionais (Fay 1994; Engelmann 1997; Kozay et al. 1997; Thorpe \& Harry 1997). Para alcançar o sucesso da cultura in vitro, são necessários requisitos essenciais para o ótimo estabelecimento das plântulas, sendo fundamental a concentração de nutrientes no meio de cultura, uma vez que cada espécie apresenta comportamento diferenciado no seu desenvolvimento devido às características genéticas (Kozay et al. 1997; Fortes \& Pereira 2001). Um dos meios mais empregados para a propagação in vitro de diversas espécies vegetais é o meio MS (Murashige \& Skoog 1962), considerado um substrato nutritivo rico em sais minerais. Porém, o excesso de nutrientes minerais e, especialmente, de sais nitrogenados no meio de cultivo pode ser prejudicial para as plântulas micropropagadas (Sakuta et al. 1987; Avila et al. 1998; Cazetta et al. 1999; Ali et al. 2000). Por outro lado, diluições do meio MS têm sido efetivas para micropropagação de plântulas (Grattapaglia \& Machado 1998), como demonstrado em estudos de bromélias (Mercier \& Kerbauy 1994; Endres \& Mercier 2001b; Tamaki et al. 2007; Kurita et al. 2014; Martins et al. 2015) e orquídeas (Stancato \& Faria 1996; Unemoto et al. 2007; Sorace et al. 2008; Endres Júnior et al. 2014).

Após a cultura in vitro, as plântulas precisam ser transferidas para a condição ex vitro. Durante esta fase, condições abióticas como a umidade relativa do ar, a intensidade luminosa e a troca de gases sofrem grandes alterações, sendo fatores limitantes para a sobrevivência das plântulas (Lakso et al. 1986). Dessa forma, a exposição gradual durante o processo de aclimatização das 
plântulas ao ambiente externo permite aumentar a sobrevivência dos indivíduos (Grattapaglia \& Machado 1998), facilitando o estabelecimento das plântulas em ambiente ex vitro, para posterior utilização em programas de conservação de espécies ameaçadas, por meio da reintrodução no ambiente natural (Benson 1999).

O presente estudo teve por objetivo avaliar a influência de diferentes concentrações de macronutrientes sobre o desenvolvimento in vitro $\mathrm{e}$ a sobrevivência ex vitro de plântulas de $V$. incurvata Gaudich., visando à conservação desta bromélia epifítica endêmica da Floresta Atlântica.

\section{Material e Métodos}

Obtenção, desinfestação e semeadura das sementes

Cápsulas maduras de Vriesea incurvata foram coletadas de indivíduos de uma população estabelecida no trecho superior da Bacia Hidrográfica do Rio dos Sinos, no município de Caraá, na região litoral norte do estado do Rio Grande do Sul, Brasil. Após lavagem em água corrente com detergente comercial e enxágue em água destilada por três vezes, as cápsulas foram levadas à câmara de fluxo laminar, onde foram esterilizadas por 30 segundos em álcool etílico $70 \%$ e, em seguida, submersas em hipoclorito de sódio $4 \%$ acrescido de $0,1 \%$ de detergente Tween ${ }^{\circledR} 20$ por 15 minutos. Após, as cápsulas foram lavadas quatro vezes em água destilada autoclavada e abertas com auxílio de bisturi, para a retirada das sementes (Droste et al. 2005). As sementes tiveram os apêndices plumosos retirados e foram semeadas em placa de petri com $30 \mathrm{~mL}$ de meio MS (Murashige \& Skoog 1962) para germinação, conforme descrito por Bencke \& Droste (2008; Fig. 1a). As culturas permaneceram em condições controladas, com intensidade luminosa de $60 \mu \mathrm{mol}$ $\mathrm{m}^{-2} \mathrm{~s}^{-1}$, fotoperíodo de 12 horas e temperatura de 26 $\pm 1^{\circ} \mathrm{C}$ durante 60 dias. Após este período, o número de sementes germinadas foi registrado.

\section{Experimento com diferentes concentrações de macronutrientes \\ Plântulas com 1,0 $\pm 0,2 \mathrm{~cm}$ de altura (Fig.} 1b) foram cultivadas em frascos contendo $30 \mathrm{~mL}$ de meio MS, acrescido de $30 \mathrm{~g} \mathrm{~L}^{-1}$ de sacarose, 4 $\mathrm{g} \mathrm{L}^{-1}$ de Phytagel ${ }^{\mathrm{TM}}, 5 \mathrm{~g} \mathrm{~L}^{-1}$ de carvão ativado e $\mathrm{pH}$ ajustado em 6,4 antes da esterilização em autoclave. A formulação completa dos sais do meio MS (meio denominado 100MS) foi utilizada como referência e os demais tratamentos consistiram na redução das concentrações dos macronutrientes (25 e 50\%: meios denominados $25 \mathrm{M} \mathrm{e} 50 \mathrm{M}$, respectivamente) ou apenas dos sais nitrogenados ( 25 e $50 \%$ : meios denominados $25 \mathrm{~N}$ e $50 \mathrm{~N}$, respectivamente; Tab. 1). Para cada tratamento, foram cultivados 70 indivíduos, distribuídos em grupos de cinco em 14 frascos (volume $200 \mathrm{~mL}$ ) totalizando 350 plântulas (Fig. 1c). A cada 60 dias, foi realizado um sub-cultivo e, ao término de 180 dias, foram mensurados comprimento da parte aérea (CPA), número de folhas (NF), número de raízes (NR), comprimento da raiz maior (CRM) e massa fresca (MF) de cada indivíduo.

Após o registro dos dados relativos aos parâmetros morfológicos acima, as plântulas foram submetidas à aclimatização conforme metodologia descrita por Sasamori et al. (2014), sendo plantadas em grupos de 15 indivíduos em substrato comercial (Carolina Soil ${ }^{\circledR}$, a base de turfa e vermiculita) em duas bandejas plásticas transparentes com tampa $(24 \mathrm{~cm} \times 18 \mathrm{~cm}, 10 \mathrm{~cm}$ de altura) por tratamento. As plântulas permaneceram em aclimatização no laboratório, sob temperatura controlada $\left(26 \pm 1^{\circ} \mathrm{C}\right)$ e com retenção de $70 \%$ da luz natural por meio da tela de polipropileno. As bandejas permaneceram fechadas com as tampas transparentes por 30 dias, para proporcionar maior umidade junto às plântulas e posteriormente a este período, as bandejas foram abertas gradualmente para expor os indivíduos em contato com o ar atmosférico. A irrigação das plântulas foi realizada manualmente, mantendo o substrato sempre úmido e as adubações foliares foram realizadas quinzenalmente com o fertilizante comercial Peter ${ }^{\circledR}$ profissional $\left(1 \mathrm{~g} \mathrm{~L}^{-1}\right)$. As plântulas permaneceram em aclimatização por um período de 150 dias (Sasamori et al. 2014), sendo registrados os dados de sobrevivência dos indivíduos provindos de cada tratamento in vitro (Fig. 1d,e).

\section{Análise estatística}

Os dados de sobrevivência das plântulas aclimatizadas foram transformados em porcentagens. Os dados dos parâmetros morfológicos foram comparados pelo teste de Kruskal-Wallis seguido pelo teste de StudentNewman-Keuls, ao nível de 5\% de probabilidade. A análise de regressão linear múltipla foi realizada para verificar a possível relação entre a massa fresca e os demais parâmetros (comprimento da parte aérea, número de folhas, comprimento da raiz maior e número de raízes). Os tratamentos foram agrupados em função das distâncias euclidianas 


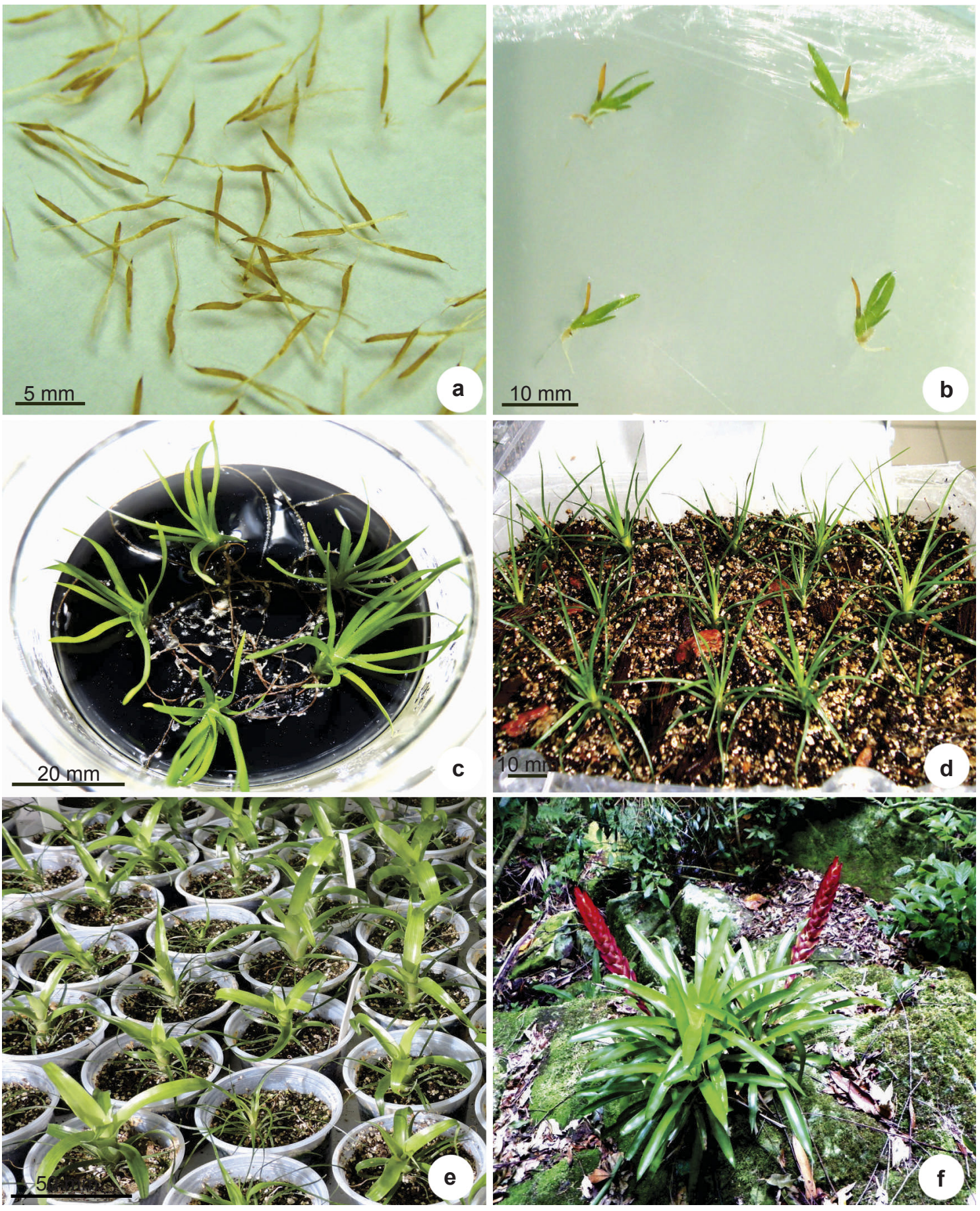

Figura 1 - a. sementes de Vriesea incurvata; b. plântulas de V. incurvata germinadas aos 60 dias; c. plântulas após 180 dias de cultivo in vitro; d. aclimatização das plântulas em substratos por 150 dias; e. plântulas cultivadas após a aclimatização; f. $V$. incurvata em ambiente natural no município de Caraá, Rio Grande do Sul.

Figure 1 - a. Vriesea incurvata seeds; b. V. incurvata plantlets germinated after 60 days; c. plantlets after 180 days of in vitro culture; d. plantlet acclimatization on substrates for 150 days; e. plantlets grown after acclimatization; f. $V$. incurvata in its natural environment in the municipality of Caraá, Rio Grande do Sul. 
Tabela 1 - Composição do meio MS (Murashige \& Skoog 1962) com a formulação completa e as reduções dos macronutrientes ou sais nitrogenados para a propagação in vitro de Vriesea incurvata.

Table 1 - Composition of MS medium (Murashige \& Skoog 1962) with complete formulation and the reduction of macronutrients or nitrogen salts for in vitro propagation of Vriesea incurvata.

\begin{tabular}{|c|c|c|c|c|c|}
\hline \multicolumn{6}{|c|}{ Tratamentos } \\
\hline Componentes & 100MS & $50 M$ & $25 M$ & $50 N$ & $25 \mathrm{~N}$ \\
\hline \multicolumn{6}{|c|}{ Macronutrientes $\left(\mathrm{mg} \mathrm{L}^{-1}\right)$} \\
\hline $\mathrm{NH}_{4} \mathrm{NO}_{3}$ & 1650 & 825 & 412,5 & 825 & 412,5 \\
\hline $\mathrm{KNO}_{3}$ & 1900 & 950 & 475 & 950 & 475 \\
\hline $\mathrm{CaCl}_{2} 2 \mathrm{H}_{2} \mathrm{O}$ & 440 & 220 & 110 & 440 & 440 \\
\hline $\mathrm{MgSO}_{4} 7 \mathrm{H}_{2} \mathrm{O}$ & 370 & 185 & 92,5 & 370 & 370 \\
\hline $\mathrm{KH}_{2} \mathrm{PO}_{4}$ & 170 & 85 & 42,5 & 170 & 170 \\
\hline \multicolumn{6}{|c|}{ Micronutrientes $\left(\mathrm{mg} \mathrm{L}^{-1}\right)$} \\
\hline $\mathrm{MnSO}_{4} \cdot 4 \mathrm{H}_{2} \mathrm{O}$ & & & 22,300 & & \\
\hline $\mathrm{ZnSO}_{4} \cdot 7 \mathrm{H}_{2} \mathrm{O}$ & & & 8,600 & & \\
\hline $\mathrm{H}_{3} \mathrm{BO}_{3}$ & & & 6,200 & & \\
\hline KI & & & 0,830 & & \\
\hline $\mathrm{Na}_{2} \mathrm{MoO}_{4} 2 \mathrm{H}_{2} \mathrm{O}$ & & & 0,250 & & \\
\hline $\mathrm{CuSO}_{4} \cdot 5 \mathrm{H}_{2} \mathrm{O}$ & & & 0,025 & & \\
\hline $\mathrm{CoCl}_{2} \cdot 6 \mathrm{H}_{2} \mathrm{O}$ & & & 0,025 & & \\
\hline $\mathrm{Na}_{2}$ EDTA $\cdot 2 \mathrm{H}_{2} \mathrm{O}$ & & & 37,3 & & \\
\hline $\mathrm{FeSO}_{4} \cdot 7 \mathrm{H}_{2} \mathrm{O}$ & & & 27,8 & & \\
\hline
\end{tabular}

utilizando análise de agrupamento hierárquico com padronização das variáveis. As análises de KruskalWallis e de agrupamento foram realizadas com o uso do programa BioEstat versão 5.3, e a análise de regressão linear múltipla foi realizada com o uso do programa SPSS versão 20.

\section{Resultados e Discussão}

A germinação das sementes de $V$. incurvata foi de $95 \%$ após 60 dias de cultivo in vitro, pelo menos duas vezes superior aos maiores percentuais registrados em hábitats naturais da espécie, sob o dossel de floresta ombrófila densa aluvial e em diferentes substratos, em que porcentagens de germinação entre $8,7 \%$ e $40,5 \%$ foram relatadas (Muraro et al. 2014). De um modo geral, diversas espécies de Vriesea Lindl. apresentam baixas porcentagens de germinação no ambiente natural (Mekers 1977; Mercier \& Kerbauy 1995), enquanto que a cultura in vitro proporciona a germinação de um maior número de sementes em menor espaço de tempo (Mercier \& Kerbauy 1995). De forma semelhante a $V$. incurvata, as bromélias $V$. gigantea Gaudich. (Droste et al. 2005), Pitcairnia flammea Lindl. (Pereira et al. 2011), Aechmea blanchetiana (Baker) L.B.Sm. e A. distichantha Lem. (SantaRosa et al. 2013) apresentaram, respectivamente, $94,99,99$ e $62 \%$ de germinação em meio MS. A alta produção de sementes por fruto da espécie (Reitz 1983; Negrelle \& Muraro 2006), associada à elevada taxa de germinação in vitro permite a obtenção de um grande número de indivíduos, sem a necessidade de multiplicação via indução de brotos laterais, geralmente associada ao uso de reguladores de crescimento (Grattapaglia \& Machado 1998; Droste et al. 2005). A propagação a partir de sementes permite a manutenção da variabilidade genética dos indivíduos propagados, que se tornam interessantes para programas de conservação in situ, por meio da reintrodução em ambiente natural (Benson 1999; Pinto et al. 2010). O cultivo de plântulas na presença de diferentes concentrações de macronutrientes não influenciou negativamente a sobrevivência das 
Tabela 2 - Valores (média \pm desvio padrão) do comprimento da parte aérea, número de folhas, comprimento da raiz maior, número de raízes e massa fresca de plântulas de Vriesea incurvata após 180 dias de micropropagação em meio MS com diferentes concentrações de macronutrientes.

Table 2 - Values (mean \pm standard deviation) of length of the aerial part, number of leaves, longest root length, number of roots and fresh mass of Vriesea incurvata plantlets after 180 days of micropropagation on MS medium with different concentrations of macronutrients.

\begin{tabular}{lccccc}
\hline Tratamento & $\begin{array}{c}\text { Comprimento da } \\
\text { parte aérea }(\mathbf{c m})\end{array}$ & $\begin{array}{c}\text { Número de } \\
\text { folhas }\end{array}$ & $\begin{array}{c}\text { Comprimento da } \\
\text { raiz maior }(\mathbf{c m})\end{array}$ & $\begin{array}{c}\text { Número de } \\
\text { raízes }\end{array}$ & $\begin{array}{c}\text { Massa fresca } \\
(\mathbf{m g})\end{array}$ \\
\hline $25 \mathrm{M}$ & $3,9 \pm 0,7 \mathrm{a}$ & $12,7 \pm 2,5 \mathrm{ab}$ & $4,3 \pm 1,5 \mathrm{~cd}$ & $3,8 \pm 1,2 \mathrm{ab}$ & $88 \pm 37 \mathrm{a}$ \\
$50 \mathrm{M}$ & $3,3 \pm 0,6 \mathrm{bc}$ & $12,8 \pm 2,1 \mathrm{a}$ & $4,4 \pm 1,3 \mathrm{bc}$ & $3,6 \pm 0,9 \mathrm{ab}$ & $67 \pm 28 \mathrm{~b}$ \\
$25 \mathrm{~N}$ & $3,8 \pm 0,8 \mathrm{a}$ & $13,8 \pm 5,0 \mathrm{a}$ & $5,4 \pm 1,5 \mathrm{a}$ & $4,1 \pm 1,5 \mathrm{a}$ & $91 \pm 41 \mathrm{a}$ \\
$50 \mathrm{~N}$ & $3,4 \pm 0,8 \mathrm{~b}$ & $12,5 \pm 2,7 \mathrm{ab}$ & $4,9 \pm 1,8 \mathrm{ab}$ & $3,5 \pm 1,1 \mathrm{~b}$ & $84 \pm 107 \mathrm{~b}$ \\
$100 \mathrm{MS}$ & $3,0 \pm 0,7 \mathrm{c}$ & $11,9 \pm 2,1 \mathrm{~b}$ & $3,6 \pm 1,2 \mathrm{~d}$ & $3,0 \pm 1,2 \mathrm{c}$ & $55 \pm 26 \mathrm{c}$ \\
$\mathrm{H}$ & 46,9822 & 9,8049 & 34,3111 & 22,2171 & 42,7541 \\
$\mathrm{P}$ & $<0,001$ & 0,0438 & $<0,001$ & 0,0002 & $<0,001$ \\
\hline
\end{tabular}

Valores médios seguidos pela mesma letra não diferem significativamente de acordo com o teste de Student-Newman-Keuls ( $\mathrm{p}<0,05$ ).

plântulas de V. incurvata, que foi de $100 \%$ em todos os tratamentos. Também não foram observadas clorose e necrose nas folhas das plântulas (Fig. 1c), mesmo nos meios com as menores concentrações de macronutrientes, indicando que as plântulas não apresentaram deficiência de nutrientes reguladores de processos metabólicos, como nitrogênio, fósforo, potássio, cálcio, magnésio e enxofre (Taiz \& Zeiger 2004; Marenco \& Lopes 2011; Marschner 2012). Porém, a influência dos diferentes tratamentos pode ser observada em todos os parâmetros morfológicos avaliados nas plântulas. Os valores médios registrados para comprimento da parte aérea e massa fresca foram significativamente maiores quando as plântulas foram cultivadas no meio $25 \mathrm{~N}$ $(\mathrm{CPA}=3,8 \mathrm{~cm} ; \mathrm{MF}=91 \mathrm{mg}$, respectivamente), bem como no meio $25 \mathrm{M}(\mathrm{CPA}=3,9 \mathrm{~cm} ; \mathrm{MF}=$ $88 \mathrm{mg}$, respectivamente). Os tratamentos com os meios $50 \mathrm{~N}$ e $50 \mathrm{M}$ proporcionaram plântulas com valores estatisticamente intermediários para comprimento da parte aérea e massa fresca, enquanto que o meio $100 \mathrm{MS}$ não se mostrou benéfico para o crescimento das plântulas, que apresentaram valores significativamente menores para comprimento da parte aérea $(\mathrm{CPA}=3 \mathrm{~cm}) \mathrm{e}$ massa fresca (MF $55 \mathrm{mg}$; Tab. 2). O número de folhas produzidas por plântula foi semelhante nos diferentes tratamentos e as médias variaram de 11,9 a 13,8. As plântulas dos tratamentos com redução de macronutrientes ou apenas de sais nitrogenados não apresentaram diferenças significativas entre si. Entretanto, quando comparadas aos indivíduos propagados no meio $100 \mathrm{MS}$, aqueles cultivados nos meios $25 \mathrm{~N}$ e $50 \mathrm{M}$ apresentaram números de folhas significativamente maiores (Tab. 2).

Os resultados registrados para Vriesea incurvata corroboram com a constatação de que menores concentrações de macronutrientes beneficiam o crescimento e o desenvolvimento in vitro de diversas espécies (Torres et al. 1998), inclusive de bromeliáceas (Mercier \& Kerbauy 1994; Tamaki et al. 2007; Kurita et al. 2014; Martins et al. 2015). Indivíduos de $A$. bromeliifolia (Rudge) Baker apresentaram maior crescimento da parte aérea e mais massa seca de raízes e da parte aérea em meio MS contendo de zero a $50 \%$ da concentração original de macronutrientes (Fráguas et al. 2002). Para A. blanchetiana, o aumento gradativo da concentração de sais nitrogenados no meio MS levou ao decréscimo linear dos parâmetros morfológicos avaliados, sendo o meio com a menor concentração de sais nitrogenados $(12,5 \%)$ considerado adequado para o cultivo desta bromélia (Kanashiro et al. 2007). Em um estudo de micropropagação de Alcantarea imperialis (Carriere) Harms em meio MS, os tratamentos com 25 e $100 \%$ de sais nitrogenados proporcionaram o maior crescimento dos indivíduos (Kurita \& Tamaki 2014). Para Nidularium minutum Mez, foi relatado maior desenvolvimento das plântulas no meio MS com metade da concentração original dos macronutrientes em comparação às plântulas propagadas nos meios MS completos e Knudson (Knudson 1946); (Kurita et al. 2014). Especificamente o nitrogênio influencia diretamente no desenvolvimento das plântulas 
dependendo da sua concentração disponível no meio (Avila et al. 1998; Cazetta et al. 1999; Ali et al. 2000), uma vez que altas concentrações de amônia e nitrato podem ser prejudiciais para o crescimento dos indivíduos (Sakuta et al. 1987).

A adaptação fisiológica de bromélias epífitas pode ser um fator importante na menor exigência de nutrientes minerais. De modo geral, bromélias tanque epifíticas, como Vriesea incurvata, obtêm nutrientes por meio da intercepção de elementos de origem atmosférica (Jordan et al. 1980; Oliveira \& Coelho Neto 2001) e da lixiviação de substâncias presentes no tronco e nas folhas do forófito hospedeiro (Benzing 1973), tendo como veículo transportador a água da chuva. Além disso, o material orgânico resultante da decomposição de pequenos animais e de vegetais também é depositado sobre os epífitos (Nadkarni 1981, 1984). Os nutrientes acumulados nos espaços entre as folhas das bromélias tanque podem ser absorvidos por meio dos tricomas presentes na base foliar. Desse modo, no ambiente natural, espécies epifíticas estão expostas constantemente ao estresse da carência nutricional e apresentam maior eficiência na absorção de nutrientes (Benzing 2000). V. gigantea, uma bromélia tanque epífita demonstrou maior tolerância à escassez de nitrogênio quando comparada à espécie terrícola Ananas comosus (L.) Merr. em um estudo sob condições controladas (Endres \& Mercier 2001a).

Em relação à formação do sistema radicular nas plântulas de $V$. incurvata, as concentrações de macronutrientes menores do que a original no meio MS foram benéficas. $\mathrm{O}$ tratamento $25 \mathrm{~N}$ proporcionou maior número de raízes por plântula $(\mathrm{NR}=4,1)$, sem diferir significativamente dos meios $25 \mathrm{M}$ e $50 \mathrm{M}$ ( $\mathrm{NR}=3,8$ e 3,6 , respectivamente). $\mathrm{O}$ comprimento da raiz maior foi superior no meio $25 \mathrm{~N}(\mathrm{CRM}=5,4 \mathrm{~cm})$, porém sem diferir significativamente do meio $50 \mathrm{~N}(\mathrm{CRM}=4,9 \mathrm{~cm})$. De outra forma, o tratamento com os sais completos do meio MS proporcionou menor número de raízes por plântula $(\mathrm{NR}=3)$ e menor comprimento da raiz maior por plântula $(\mathrm{CRM}=3,6 \mathrm{~cm}$; Tab. 2). $\mathrm{O}$ uso de meios com concentrações reduzidas de macronutrientes pode estimular a formação e o crescimento das raízes (Grattapaglia \& Machado 1998), importante para o contato com o substrato (Zhang et al. 2010). Tamaki et al. (2007) observaram o acúmulo cerca de 2,5 vezes superior da auxina ácido indolacético nas raízes de $A$. comosus cultivada na ausência de nitrogênio, sugerindo que tal hormônio pode ter sido translocado das folhas para as raízes. As auxinas são responsáveis pelo alongamento celular e as raízes são sensíveis a elas (Davies 2010; Marschner 2012). Ressaltase que o sistema radicular contribui com maior sobrevivência das plântulas durante a fase de aclimatização ex vitro (Besson et al. 2010).

As plântulas cultivadas nos meios $25 \mathrm{~N}$ e $25 \mathrm{M}$ apresentaram as maiores massas frescas $(\mathrm{MF}=91 \mathrm{e}$ $88 \mathrm{mg}$, respectivamente), enquanto que os menores valores foram registrados para as plântulas mantidas em meio 100MS (MF $=55$ mg; Tab. 2). A regressão linear múltipla indicou que o comprimento da parte aérea, o número de folhas e o número de raízes por plântula foram as variáveis mais importantes. $\mathrm{O}$ modelo mostrou que o comprimento da parte aérea foi responsável por $60 \%$ do coeficiente de determinação $\left(r^{2}\right.$ ajustado $\left.=0,601 ; p<0,001\right)$, enquanto que o número de folhas adicionou $7 \%\left(\mathrm{r}^{2}\right.$ ajustado $=0,669 ; \mathrm{p}<0,001)$ e o número de raízes adicionou $4 \%\left(r^{2}\right.$ ajustado $\left.=0,712 ; p<0,001\right)$ a este coeficiente. Desta forma, a massa fresca foi predita por uma combinação linear destas três variáveis, conforme a equação: $\mathrm{MF}=-6,361+1,336 \mathrm{CPA}+$ $0,698 \mathrm{NF}+0,211 \mathrm{NR}$, onde as siglas MF, CPA, NF e NR indicam massa fresca, comprimento da parte aérea, número de folhas por plântula e número de raízes por plântula, respectivamente.

Após aclimatização ex vitro por 150 dias, altas porcentagens de sobrevivência de indivíduos de $V$. incurvata foram registradas. Todos os indivíduos cultivados nos meios $25 \mathrm{M}$ e $25 \mathrm{~N}$ sobreviveram e, para as plântulas provindas dos tratamentos $50 \mathrm{M}$ e $50 \mathrm{~N}$, foram verificados $96,7 \%$ de sobrevivência, respectivamente. A menor porcentagem de sobrevivência foi registrada para as plântulas provindas do meio com a concentração original de macronutrientes $(93,3 \%)$. Resultados similares foram obtidos para indivíduos de Nidularium minutum cultivados em $50 \%$ dos macronutrientes originais do meio MS, que apresentaram 100\% de sobrevivência após 90 dias de aclimatização (Kurita et al. 2014). Plântulas micropropagadas de Acanthostachys strobilacea (Schult. \& Schult.f.) Klotzsch aclimatizadas em substrato com irrigação de diferentes diluições do meio MS, apresentaram em média $95 \%$ de sobrevivência ao término de 240 dias (Santos et al. 2010). No entanto, espécies de bromeliáceas propagadas in vitro também podem apresentar porcentagens de sobrevivência inferiores, tais como Dyckia maritima Baker, que apresentou $63 \%$ a $91 \%$ de sobrevivência em diferentes substratos após 120 dias (Silva et al. 2008 ) e A. blanchetiana, para a qual $65 \%$ a $85 \%$ 
dos indivíduos sobreviveram após 120 dias ex vitro (Tavares et al. 2008). A etapa de aclimatização de plântulas provindas da cultura in vitro é considerada um processo intermediário importante para o estabelecimento das plantas no ambiente natural, uma vez que neste período podem ocorrer perdas elevadas de indivíduos (Pospísilová et al. 1999). Durante a cultura in vitro, as plântulas crescem sob condições especiais, sendo expostas a elevada umidade relativa do ar, altos níveis de nutrientes orgânicos e inorgânicos, carboidrato como fonte de carbono, havendo reduzidas trocas gasosas e baixa luminosidade disponível (Ziv 1994; Grattapaglia \& Machado 1998; Pospísilová et al. 1999), além de estômatos poucos funcionais, bem como cutícula delgada e parênquima paliçádico pouco desenvolvido (Díaz-Peres et al. 1995). A brusca mudança para as condições abióticas no ambiente ex vitro é fator limitante para a sobrevivência das plântulas (Lakso et al. 1986; Assis et al. 2009), pois impõe mudanças fisiológicas e morfológicas às plântulas (Debergh 1991).

A análise de agrupamentos com todos os parâmetros avaliados nas plântulas (comprimento da parte aérea, número de folhas por plântula, comprimento da raiz maior, número de raízes por plântula, massa fresca e sobrevivência na etapa de aclimatização) demonstrou a separação dos

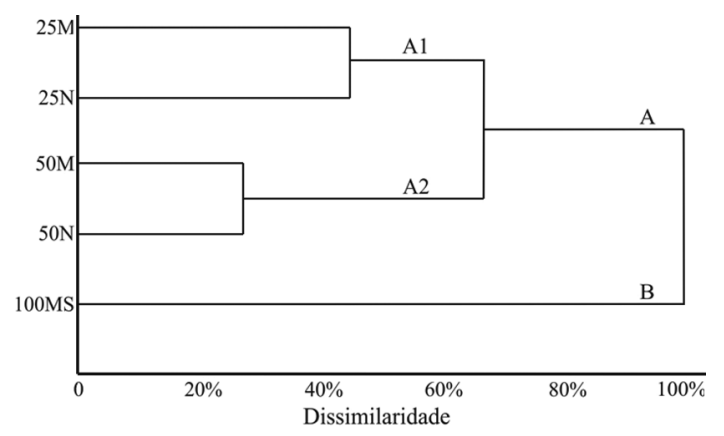

Figura 2 - Dendrograma obtido a partir da análise de agrupamento hierárquico de tratamentos de meio de cultura com padronização variável, utilizando o índice de dissimilaridade com base na distância Euclidiana. N = porcentagens de sais nitrogenados do meio $\mathrm{MS} ; \mathrm{M}=$ porcentagens de macronutrientes do meio MS; MS = formulação completa do meio MS.

Figure 2 - Dendrogram obtained from the hierarchical cluster analysis of culture medium treatments with variable standardization, using the dissimilarity index based on Euclidean distance. $\mathrm{N}=$ nitrogen salts percentages of MS medium; $\mathrm{M}=$ macronutrient percentages of MS medium; MS = complete formulation of MS medium. tratamentos em A e B (Fig. 2). O grupo A se dividiu em dois sub-grupos, em que os meios $25 \mathrm{M}$ e $25 \mathrm{~N}$ formaram o sub-grupo A1 pela influência similar destes tratamentos sobre os parâmetros avaliados nas plantas e os meios $50 \mathrm{M}$ e $50 \mathrm{~N}$ se agruparam (A2) e se diferenciaram de A1. O meio 100MS ficou isolado dos demais tratamentos (B).

A redução de todos os sais macronutrientes ou apenas dos sais nitrogenados para $25 \%$ da concentração original no meio MS mostrou-se adequada para os parâmetros avaliados no presente estudo, promovendo o crescimento da parte aérea, a produção de folhas, a formação e o crescimento de raízes, bem como beneficiando a sobrevivência das plântulas na aclimatização ex vitro. Os resultados apontaram a importância de avaliar a composição mineral do meio de cultura, visando a determinar as condições ótimas para o processo de propagação de $V$. incurvata a partir de sementes para fins comerciais bem como para iniciativas de conservação da espécie.

\section{Agradecimentos}

Os autores agradecem à Coordenação de Aperfeiçoamento de Pessoal de Nível Superior (CAPES) e Fundação de Amparo à Pesquisa do estado do Rio Grande do Sul (FAPERGS), a concessão de bolsa de Mestrado (CAPES/ FAPERGS) para o primeiro autor. E à Fundação de Amparo à Pesquisa do Estado do Rio Grande do Sul (FAPERGS), a bolsa de Iniciação Científica (PROBIC) para o segundo autor.

\section{Referências}

Ali, I.E.A.; Kafkafi, U.; Yamaguchi, I.; Sugimoto, Y. \& Inanaga, S. 2000. Growth, transpiration, rootborne cytokinins and gibberellins, and nutrients compositional changes in sesame exposed to low root-zone temperature under different ratios of nitrate: ammonium supply. Journal of Plant Nutrition 23: 123-140.

Assis, A.M.; Faria, R.T.; Unemoto, L.K.; Colombo, L.A. \& Lone, A.B. 2009. Aclimatização de bastão-doimperador (Etlingera elatior) em substratos à base de coco. Acta Scientiarum. Agronomy 31: 43-47.

Avila, A.D.; Pereira, S.M. \& Arguello, J.A. 1998. Nitrogen concentration and proportion of $\mathrm{NH}_{4}-\mathrm{N}$ affect potato cultivar response in solid and liquid media. HortScience 33: 336-338.

Bencke, M. \& Droste, A. 2008. Otimização da micropropagação de Vriesea gigantea Gaudich. (Bromeliaceae), uma espécie ameaçada de extinção, nativa do Rio Grande do Sul, Brasil. Revista Pesquisas, Botânica 59: 299-306. 
Benson, E.E. 1999. Plant conservation biotechnology. Taylor \& Francis, London. 309p.

Benzing, D.H. 1973. Mineral nutrition and related phenomena in Bromeliaceae and Orchidaceae. Quarterly Review of Biology 48: 277-290.

Benzing, D.H. 2000. Bromeliaceae: profile of an adaptive radiation. Cambridge University Press, Cambridge. 690p.

Besson, J.C.F.; Oliveira, L.K.; Bonett, L.P. \& Stefanello, S. 2010. Fontes e concentração de carboidratos no crescimento vegetativo e no enraizamento in vitro de Miltonia flavescens Lindl. Revista Brasileira de Biociências 8: 9-13.

BFG. 2015. Growing knowledge: an overview of Seed Plant diversity in Brazil. Rodriguésia 66: 1085-1113.

Bourscheid, K. 2008. Levantamento das Bromeliaceae Juss. da fazenda Acaraú, Bertioga, São Paulo. Dissertação de Mestrado em Biologia Vegetal Instituto de Botânica. Universidade Federal de Santa Catarina, Florianópolis. 82p.

Cazetta, J.O.; Seebauer, J.R. \& Below, F.E. 1999. Sucrose and nitrogen supplies regulate growth of maize kernels. Annals of Botany 84: 747-754.

Davies, P. 2010. The plant hormones: their nature, occurrence, and functions. Cornell University Department of Plant Biology, Ithaca. 802p.

Debergh, P.C. 1991. Acclimatization techniques of plants from in vitro. Acta Horticulturae 289: 291-300.

Díaz-Pérez, J.C.; Sutter E.G. \& Shackel, K.A. 1995. Acclimatization and subsequent gas exchange, water relations, survival and growth of microcultured apple plantlets after transplanting them in soil. Physiologia Plantarum 95: 225-232.

Droste, A.; Silva, A.M.; Matos, A.V. \& Almeida, J.W. 2005. In vitro culture of Vriesea gigantea and Vriesea philippocoburgii: two vulnerable bromeliads native to southern Brazil. Brazilian Archives of Biology and Technology 48: 717-722.

Endres, L. \& Mercier, H. 2001a. Ammonium and urea as nitrogen sources for bromeliads. Journal of Plant Physiology 158: 205-212.

Endres, L. \& Mercier, H. 2001b. Influence of nitrogen forms on the growth and nitrogen metabolism of bromeliads. Journal of Plant Nutrition 24: 29-42.

Endres Júnior, D.; Sasamori, M.H. \& Droste, A. 2014. In vitro propagation of Anathallis adenochila (Loefgr.) F. Barros (Orchidaceae), a species endemic to southern and southeastern Brazil. Acta Botanica Brasilica 28: 489-494.

Engelmann, F. 1997. Present development and use of in vitro culture techniques for the conservation of plant genetic resources. Acta Horticulturae 447: 471-475.

Fay, M.F. 1994. In what situations is in vitro culture appropriate to plant conservation? Biodiversity and Conservation 3: 176-183.

Fortes, G.R.L. \& Pereira, J.E.S. 2001. Estabelecimento in vitro da ameixeira cv. América. Revista Brasileira de Fruticultura 23: 183-185.
Forzza, R.C.; Costa, A.F.; Leme, E.M.C.; Versieux, L.M.; Wanderley, M.G.L.; Louzada, R.B.; Monteiro, R.F.; Judice, D.M.; Fernandez, E.P.; Borges, R.A.X.; Penedo, T.S.A.; Monteiro, N.P. \& Moraes, M.A. 2013. Bromeliaceae. In: Martinelli, G. \& Moraes, M.A. (ed.). Livro Vermelho da Flora do Brasil. Instituto de Pesquisas Jardim Botânico do Rio de Janeiro, Rio de Janeiro. Pp. 315-396.

Fráguas, C.B.; Pasqual, M.; Dutra, L.F. \& Chagas, E.A. 2002. Desenvolvimento in vitro de plântulas de bromélia: sacarose e concentrações do meio MS. Revista Científica Rural 7: 55-63.

Fundação SOS Mata Atlântica. 2015. Disponível em $<$ http://www.sosma.org.br/nossa-causa/a-mataatlantica/>. Acesso em 26 abril 2015.

Fundação SOS Mata Atlântica \& Instituto Nacional de Pesquisas Espaciais - INPE. 2014. Atlas dos remanescentes florestais da Mata Atlântica: período 2012-2013. Fundação SOS Mata Atlântica \& São José dos Campos, INPE, São Paulo. 60p.

Grattapaglia, D. \& Machado, M.A. 1998. Micropropagação. In: Torres, A.C.; Caldas, L.S. \& Buso, J.A. (eds.). 1998. Cultura de tecidos e transformação genética de plantas. $2^{\text {nd }}$ ed. Embrapa, Brasília. Pp. 183-260.

Harper, J.L. 1977. Population biology of plants. Academic Press, NewYork. 892p.

Instituto Brasileiro de Florestas. 2015. Disponível em $<$ http://www.ibflorestas.org.br/bioma-mata-atlantica. html $>$. Acesso em 26 abril 2015.

Jordan, C.F.; Herrera, R. \& Medina, E. 1980. Nutrient scavenging of rainfall by the canopy of an Amazonian rain forest. Biotropica 12: 61-66.

Kanashiro, S.; Ribeiro, R.C.S.; Gonçalves, A.N.; Dias, C.T.S. \& Jocys, T. 2007. Efeitos de diferentes concentrações de nitrogênio no crescimento de Aechmea blanchetiana (Baker) L.B. Sm. cultivada in vitro. Hoehnea 34: 59-66.

Kersten, R.A. 2010. Epífitas vasculares: histórico, participação taxonômica e aspectos relevantes, com ênfase na Mata Atlântica. Hoehnea 37: 9-38.

Knudson, L. 1946. A new nutrient solution for the germination of orchid seed. American Orquid Society Bulletim 14: 214-217.

Kozay, T.; Kubota, C. \& Jeong, B.R. 1997. Environmental control for large-scale production of plants through in vitro techniques. Plant Cell, Tissue and Organ Culture 51: 49-56.

Kurita, F.M.K. \& Tamaki, V. 2014. In vitro growth of the bromeliad Alcantarea imperialis (Carrière) Harms with different concentrations of nitrogen. Acta Scientiarum. Biological Sciences 36: 279-285.

Kurita, F.M.K.; Machado, B.M.; Teixeira, N.B.; Cesar, C.G.A; Nievola, C.C. \& Tamaki, V. 2014. Fenologia, cultivo in vitro e aclimatização da bromélia ameaçada de extinção Nidularium minutum Mez. Biotemas 27: 59-69.

Lakso, A.N.; Reish, B.I.; Montensen, J. \& Roberts, M.H. 1986. Carbon dioxide enrichment for stimulation of 
growth of in vitro propagated grapevines after transfer from culture. Journal of the American Society for Horticultural Science 111: 634-638.

Luther, H. 2010. An alphabetical list of bromeliads binomials. Bromeliad Society International, Sarasota. $114 \mathrm{p}$.

Marenco, R.A. \& Lopes, N.F. 2011. Fisiologia vegetal: fotossíntese, respiração, relações hídricas e nutrição mineral. Universidade Federal de Viçosa, Viçosa. 486p.

Marschner, H. 2012. Mineral nutrition of highter plants. Academic Press, London. 672p.

Martinelli, G.; Vieira, C.M.; Gonzalez, M.; Leitman, P.; Piratininga, A.; Costa, A.F. \& Forzza, R.C. 2008. Bromeliaceae da Mata Atlântica brasileira: lista de espécies, distribuição e conservação. Rodriguésia 59: 209-258.

Martins, J.P.R.; Pasqual, M.; Martins, A.D. \& Ribeira, S.F. 2015. Effects of salts and sucrose concentrations on in vitro propagation of Billbergia zebrina (Herbert) Lindley (Bromeliaceae). Australian Journal of Crop Science 9: 85-91.

Mekers, O. 1977. In vitro propagation of some Tillandsioideae (Bromeliaceae). Acta Horticulturae 78: 311-320.

Mercier, H. \& Kerbauy, G.B. 1994. In vitro culture of Vriesea hieroglyphica, an endangered bromeliad from the Brazilian Atlantic Forest. Journal of the Bromeliad Society 44: 120-124.

Mercier, H. \& Kerbauy, G.B. 1995. The importance of tissue culture technique for conservation of endangered Brazilian bromeliads from Atlantic rain forest canopy. Selbyana 16: 147-149.

Muraro, D.; Negrelle, R.R.B. \& Anacleto, A. 2014. Germinação e sobrevivência de Vriesea incurvata Gaudich. sob dossel florestal em diferentes substratos. Scientia Agraria Paranaensis 13: 251-258.

Murashige, T. \& Skoog, F. 1962. A revised medium for rapid growth and bioassays with tobacco tissue cultures. Physiologia Plantarum 15: 473-497.

Myers, N.; Mittermeier, R.A.; Mittermeier, C.G.; Fonseca, G.A.B. \& Kent, J. 2000. Biodiversity hotspots for conservation priorities. Nature 403: 853-858.

Nadkarni, N.M. 1981. Canopy roots: convergent evolution in rainforest nutrient cicles. Science, New Series 214: 1023-1024.

Nadkarni, N.M. 1984. Epiphyte biomass and nutrient capital of a neotropical Elfin Forest. Biotrópica 16: 249-256.

Negrelle, R.R.B. \& Muraro, D. 2006. Aspectos fenológicos e reprodutivos de Vriesea incurvata Gaudich (Bromeliaceae). Acta Scientiarum. Biological Sciences 28: 95-102.

Oliveira, R.R. \& Coelho Netto, A.L. 2001. Captura de nutrientes atmosféricos pela vegetação na Ilha Grande, RJ. Revista Pesquisa, Botânica 51: 31-49.

Padilha, V. 1978. Bromeliads. Crow Publisher Inc., New York. $134 \mathrm{p}$.
Pedroso-de-Moraes, C.; Diogo, J.A.; Pedro, N.P.; Canabrava, R.I.; Martini, G.A. \& Marteline, M.A. 2009. Desenvolvimento in vitro de Cattleya loddigesii Lindl. (Orchidaceae) utilizando os fertilizantes comerciais. Revista Brasileira de Biociências 7: 67-69.

Pereira, E.O.; Lima, A.B.P.; Nogueira, E.U.; Couto, D.R. \& Soares, T.C.B. 2011. Germinação in vitro de Pitcairnia flammea (Bromeliaceae): efeito do meio de cultivo e carvão ativado. Enciclopédia Biosfera, Centro Científico Conhecer 7: 634-642.

Pinto, J.R.S.; Freitas, R.M.O. \& Praxedes, S.C. 2010. Stimulation of in vitro development of Cattleya granulosa by sucrose. General and applied Plant Physiology 36: 183-188.

Pospísilová, J.; Tichá, I.; Kadlecek, P.; Haisel, D. \& Plzáková, S. 1999. Acclimatization of micropropagated to ex vitro conditions. Biologia Plantarum 42: 481-497.

Reitz, R. 1983. Bromeliáceas e a malária-bromélia endêmica. In: Reitz, R. (ed.). Flora ilustrada catarinense. Herbário Barbosa Rodrigues, Itajaí. 518p.

Rio Grande do Sul. Decreto n ${ }^{\circ}$ 52.109, de 1 de dezembro de 2014. Declara as espécies da flora nativa ameaçadas de extinção no estado do Rio Grande do Sul. Ano LXXII. Vol. 233. Lex-Diário Oficial do Rio Grande do Sul, Porto Alegre. Pp. 2-11.

Sakuta, M.; Takagi, T. \& Komamine, A. 1987. Effects of nitrogen source on betacyanin accumulation and growth in suspension cultures of Phytolacca americana. Physiologia Plantarum 71: 459-463.

Santa-Rosa, S.; Souza, F.V.D.; Vidal, A.M.; Ledo, C.A.S. \& Santana, J.R.F. 2013. Micropropagation of the ornamental vulnerable bromeliads Aechmea blanchetiana and Aechmea distichantha. Horticultura Brasileira 31: 112-118.

Santos, D.S.; Tamali, V. \& Nievola, C.C. 2010. In vitro propagation of the ornamental bromeliad Acanthostachys strobilacea (Schult. f.) Klotzsch via nodal segments. In vitro Cellular \& Developmental Biology - Plant 46: 524-529.

Sasamori, M.H.; Endres Júnior, D. \& Droste, A. 2014. Sobrevivência e desenvolvimento de plântulas de Cattleya intermedia Graham (Orchidaceae) micropropagadas e aclimatadas em substrato com fibra de coco. Revista Pesquisas, Botânica 65: 293303.

Silva, A.L.L.; Franco, E.T.H.; Dornelles, E.B. \& Gesing, J.P.A. 2008. Micropropagação de Dyckia maritima Baker - Bromeliaceae. Iheringia, Série Botânica 63: 135-138.

Sorace, M.; Faria, R.T. de; Damasceno Júnior, C.V.; Gomes, G.P.; Barbosa, C.M.; Vieira, F.G.N.; Silva, G.L. da; Takahashi, L.S.A. \& Schnitzer, J.A. 2008. Crescimento in vitro de Oncidium baueri (Orchidaceae) em diferentes concentrações de macronutrientes e sacarose. Ciências Agrárias 29: 775-782.

Stancato, G.C. \& Faria, R.T. 1996. In vitro growth and mineral nutrition of lithophytic orchid Laelia 
cinnabarina Batem (Orchidaceae) I: Effects of macro and microelements. Lindleyana 11: 41-43.

Taiz, L. \& Zeiger, E. 2004. Fisiologia vegetal. Artmed, Porto Alegre. 719p.

Tamaki, V.; Mercier, H. \& Nievola, C.C. 2007. Cultivo in vitro de clones de Ananas comosus (L.) Merril cultivar 'Smooth Cayenne' em diferentes concentrações de macronutrientes. Hoehnea 34: 69-73.

Tavares, A.R.; Giampaoli. P.; Kanashiro, S.; Aguiar, F.F.A. \& Chu, E.P. 2008. Efeito da adubação foliar com KNO3 na aclimatização de bromélia cultivada in vitro. Horticultura Brasileira 26: 175-179.

Thorpe, T.A. \& Harry, I.S. 1997. Application of tissue culture to horticulture. Acta Horticulturae 447: 39-49.

Torres, A.C.; Caldas, L.S. \& Buso, J.A. 1998. Cultura de tecidos e transformação genética de plantas. Embrapa, Brasília. 512p.

Unemoto, L.K.; Faria, R.T. de; Vieira, A.O.S. \& Dalio, R.J.D. 2007. Propagação in vitro de orquídeas brasileiras em meio de cultura simplificado. Revista Brasileira Agrociência 13: 267-269.

Wanderley, M.G.L.; Shepherd, G.J.; Melhen, T.S. \& Giulietti, A.M. 2006. Flora Fanerogâmica do estado de São Paulo. Instituto de Botânica, São Paulo. Vol. 5, pp. 392.

Winkler, M.; Hülber, K. \& Hietz, P. 2005. Effect of canopy position on germination and seedling survival of epiphytic bromeliads in a Mexican humid Montane Forest. Annals of Botany 95: 1039-1047.

Zhang, Z.; Song, H.; Liu, Q.; Rong, X.; Guan, C.; Peng, J.; Xie, G. \& Zhang, Y. 2010. Studies on differences of nitrogen efficiency and root characteristics of oilseed rape (Brasica napus L.) cultivars in relation to nitrogen fertilization. Journal of Plant Nutrition 33: 1148-1459.

Ziv, M. 1994. In vitro Acclimatization. In: AitkenChristie, J.; Kozai, T. \& Smith, M.A.L. (ed.). Automation and environmental control in plant tissue culture. Kluwer Academic Publisher, Dordrecht. 493p. 